\title{
2. Counting the Wik: the 2001 Census in Aurukun, western Cape York Peninsula
}

\section{David Martin}

\section{Introduction}

This chapter concerns the conduct of the 2001 census in Aurukun, a predominantly Aboriginal community of over 1,000 residents in western Cape York Peninsula. Almost all of the Aboriginal residents of the Statistical Local Area (SLA) are from groups whose traditional lands lie in and around the SLA, now collectively known as Wik people (Martin 1993). Fieldwork took place over a total of five days in Aurukun between the late afternoon of Sunday 5 August and midday on Friday 10 August. Roughly 50 per cent of the time was devoted to observing the conduct of the census itself. The balance was devoted to an unrelated project.

\section{The region}

The relevant SLA comprises the whole of the Aurukun Shire lease, an extensive area bounded on the west by the Gulf of Carpentaria, and lying between the Embley River north of Aurukun, and the South Kendall (Holroyd) River between Aurukun and Pormpuraaw. At various times when past censuses have been undertaken (e.g. 1986), significant numbers of Aboriginal people have been resident on outstations situated within the SLA. In August 2001 however, for a range of reasons including ceremonial restrictions on outstations and their access roads following deaths, none of the outstations were occupied. The conduct of the census therefore focused almost entirely on the township of Aurukun itself. However, a small number of people were resident in short term or semipermanent dry season camps, most within a few kilometres of the township. Census collectors also made a special trip involving two days' driving to an Aboriginal-owned cattle station inland from Aurukun, on advice that several Aurukun people were resident there; in the event however, only two people were enumerated there. Quite a number of people had travelled overland to Pormpuraaw, a day's drive south of Aurukun, for a football carnival and had not returned to Aurukun as expected by the weekend before the census.

\section{Demographic background to the census}

A combination of reasons including the complex geography of this region, its monsoonal climate, poor regional transport links, and a range of historical and sociocultural factors, have resulted in there being a relatively low permanent Aboriginal population movement away from or into the area (Martin \& Taylor 1996; Taylor 1995), although some Aurukun Wik people now live more or less permanently in centres such as Coen, Napranum and Pormpuraaw on the fringes of Wik country, and others live further afield in centres such as Kowanyama and Mornington Island. 
There is, however, very high internal mobility. Ethnographic surveys conducted in February and June 1986, showed that some 35 per cent of the total Aurukun Aboriginal population had shifted their place of residence over the four-month period. Examination of household composition in these surveys demonstrated a frequent pattern whereby residential cores remained relatively constant, while more mobile groups (such as children and young men) moved between households (Martin 1993: 274; Martin \& Taylor 1996), a phenomenon reported elsewhere in Aboriginal Australia (Finlayson 1991; Smith 1991). Who was considered a 'visitor', and who a 'usual resident', could be just as much a function of the social and kin distance between core household residents and the individual concerned, as of whether he or she was normally resident there. In such circumstances, it is clear that the census distinction between 'usual residents' and 'visitors' can be problematic.

Moreover, daily social life was characterised by high levels of movement, with most individuals spending much of the day either in their various work places or in more-orless public spaces outside dwellings involved in socialising, playing cards and other such activities. It was often the case that residents were not in their homes well into the night, and that many dwellings would not necessarily have anyone present for most of the day.

\section{Pre-census preparation}

Preparation for the 2001 Census was complicated by the failure of the ABS to dispatch the relevant census forms to Aurukun. There was, furthermore, an Australia-wide shortage of the remote area forms, and so photocopied versions were prepared by ABS staff and air freighted to Cairns for onshipment by light aircraft to Aurukun. However, a series of unforseen logistical and other problems meant that the forms did not arrive in Aurukun until the day of the census itself, Tuesday 7 August. In the meantime, therefore, photocopies were made of the sample forms provided in the Working for the Census guide for interviewers, particularly the Dwelling Check List (see Appendix A) and the SIHF (see Appendix B), so that the necessary preparatory work could be undertaken. As it eventuated, because the photocopies were not colour coded as were the originals, considerable difficulties were occasioned for interviewercollectors (henceforth interviewers) in the field since there was no simple visual clue as to which form was which, and in particular whether each SIHF had its associated SIPFs (see Appendix C) attached.

Steps had been taken to implement pre-census training. The CFO, who was based in Cairns, had conducted a training session in Aurukun, involving the $\mathrm{CC}$ and a number of the proposed interviewers. The CC was of the view that the training had gone well, although certain of the proposed interviewers had not attended. Although the video prepared by the ABS specifically to train interviewers in the remote area methodology was apparently not shown during training, this was probably of little consequence since the situation (including cultural 'styles') in the South Australian rural Aboriginal community depicted in the video and that in Aurukun were rather different. Of course, the difficulty for the ABS, and for those involved in census collections in remote Indigenous communities, is how to ensure appropriateness of materials and training across the range of communities and situations to be encountered, while maintaining consistency and commensurability in the data ultimately collected. 
The CC had clearly put considerable effort into developing a methodology for census collection in the township at least, and (apart from the absence of forms) was well prepared. A number of potential issues had been identified prior to the census collection in meetings between the CC and the interviewers. These included the problem of how Q. 4 and Q. 5 on the SIPF treat kin relationships within households. In this regard, the advice from the $\mathrm{CFO}$ was that interviewers were to record relationships in the terms in which people themselves described them.

Problems arising from the 'married' terminology used in Q. 6 of the SIPF were seen as twofold. Firstly, the interviewers seemed prepared to accept that 'married' could encompass 'de facto', but were nonetheless concerned about the term's appropriateness; and secondly, it was felt that there could be people involved in long-term relationships but not cohabiting with their partner who might be concerned that describing themselves as 'married' could adversely impact on their welfare entitlements.

Doubts were raised about the wording of, and relationship between, the 'origin' and 'ancestry' questions (Q. 10 and Q. 13 on the SIPF). It was presumed that Q. 10 offered a 'no' option for those non-Indigenous people living in otherwise Indigenous households who preferred not to fill out a separate, standard, personal census form.

It was also felt that Q. 28, regarding the before-tax income of each individual, would pose difficulties for many people, since not only were people not necessarily aware of how much tax was deducted from their Community Development Employment Project (CDEP) and other pays, but also were not necessarily aware of the Local Government Services levy deducted by the Aurukun Shire Council.

It was felt that there would be problems in identifying precisely where people were living one year ago and at the time of the previous census, five years ago. The $\mathrm{CC}$ was proposing to use the Aurukun Council's lot numbering system within the township, but quite a few of the houses that had existed in 1996 had been demolished, and a significant number of new dwellings had been constructed in the intervening period, including over the previous 12 months. It was envisaged that during the actual census, the place(s) of residence one and five years ago might be recorded (for example) as 'Bill's place', and then a more consistent address system would be recorded on forms during the post-collection validation process. Additionally, neither the interviewers nor the CC were clear about whether the import of this question related to whether people had been living elsewhere than Aurukun five years ago, for example in other communities or on outstations, or whether it was aimed at establishing intra-community mobility.

More generally, the CC was of the view that there would be the need for several days to be devoted post-collection to the validation of information on the forms. It should be stated at this juncture that the issues identified by the $\mathrm{CC}$ and the interviewers all proved to be borne out in my observations of the actual census collection.

Despite efforts at information dissemination about the census, my own inquiries suggested that there did not seem to be much general awareness of it within the community. Prior to the actual census collection starting, only two of the dozen or so people around the township I spoke with knew about the forthcoming census, or even what a census was. 
This is not however to be taken as a criticism of those involved in preparing for the census: rather, it reflects the quite different priorities and interests of Aboriginal residents of communities such as Aurukun, and a fair level of indifference to the administrative requirements and priorities of the state.

\section{Proposed collection methodology}

The proposed methodology involved dividing the township into some 11 sectors, marked on a map of the township provided by the Aurukun Shire Council. A total of 134 dwellings had been identified from the map for Indigenous residents. The map of the township was to be used to develop a preliminary Dwelling Check List for each sector. Those of nonIndigenous (primarily staff) residents, for which the standard census forms were used, were additional, and the $\mathrm{CC}$ undertook the responsibility of providing and collecting these standard census forms.

Responsibility for filling in and collecting the forms for the Indigenous households in each sector was to be assigned to one of five two-person teams of interviewers. The CC ensured that each team had at least one person who was fluent in or had a good working knowledge of Wik Mungkan, the lingua franca of the Aboriginal residents of the area, and at least one person who was competent to fill in the SIHFs and SIPFs accurately. In some instances, this meant that teams comprised a Wik and a non-Wik person, while in others one Wik person involved satisfied both criteria and was assisted by another Wik interviewer.

In assigning interviewers to teams, the $\mathrm{CC}$ tried to ensure that the capacity of each team to operate effectively was not compromised by personal incompatibilities between team members (such as those arising from kin-based restrictions for Wik interviewers), or by potential incompatibilities between interviewers and the residents of their assigned collection sectors. An important source of such potential problems was the high level of disputation within Aurukun, structured in terms of residence in the 'topside' (eastern) and 'bottomside' (western) areas of the township. As discussed elsewhere (Martin 1993), this basic division within the township reflects long-standing patterns of political and social relations between 'topside' or inland Wik groups and 'bottomside' or coastal ones.

The census collection revolved around three key individuals; the (non-Aboriginal) CC, whose main role centred on organising the logistics and ensuring the rigour of the collection, and two Wik individuals, one male and one female, who between them had an almost encyclopaedic knowledge of kin and family relationships and of household compositions across the township. Particularly in the case of the male Wik interviewer, the knowledge gained from being a member of the Wik community resident in Aurukun had been supplemented by his long-term role within the Shire Council administration. This meant that he had an unparalleled knowledge of the kinds of information which would normally be held in administrative data sets, such as household compositions, sources of income, income levels, information on employer details, and so forth.

The census collection operation was based in the large and secure air conditioned restaurant at the rear of the Council-run tavern. Tables had been set up around the room where paperwork for each sector was kept, including a copy of the relevant section of 
the township map and ultimately the collated SIHFs and SIPFs. In the hot and dusty conditions in Aurukun, having such a facility provided an invaluable aid in maintaining a systematic and ordered approach to the collection and its associated paperwork.

It was proposed that the names of those who were normally residents of Aurukun but were absent during the week of the census (e.g. at the Pormpuraaw football carnival) would be placed on the relevant SIHF. Largely blank SIPFs would also be created for them, and interviewers would attempt to get the relevant information over the two or so weeks that it was envisaged the census collection would take to complete. The strategy was clearly based on the assumption that absent usual residents would not be enumerated elsewhere, which at least in the case of those at Pormpuraaw was certainly justified. Visitors in Aurukun households were also to be enumerated.

It was also proposed that once all the SIHFs and SIPFs had been collected, an information validation process would be conducted, involving the $\mathrm{CC}$ and the principal Aboriginal interviewer. It was intended that this exercise would focus particularly on ensuring that children had been enumerated, working from the Aboriginal collectors' knowledge of who were care-givers and which children they looked after. Another proposed aspect of the validation process was ensuring that there had been no double-counting, for example for people who moved between two or more residences on a regular basis. The final stage was to involve 'spot checking', at places such as the community store, to estimate how thoroughly the census had been done.

\section{Conduct of the census}

The CC had planned for work on the collection itself to begin first thing on the Monday morning with the development of the Dwelling Check Lists. When no interviewers had arrived at the operations centre by mid-morning, the CC drove off to look for them. It turned out that the interviewer on whom so much depended, because of the unparalleled knowledge mentioned previously, was urgently required in the Post Office to sort the incoming mail (which included Centrelink cheques). The dearth of individuals with the necessary skills and education levels is a well-documented feature of remote Aboriginal communities such as Aurukun. One consequence is the high demands and stress placed on those relatively few Aboriginal people who do have the formal capacity (and the willingness) to undertake administrative tasks. While this individual was critical to the conduct of the census, he was also essential to a number of other concurrent and ongoing community administration processes. This was also true of a number of the other Aboriginal interviewers, for whom managing their work for the census also necessarily included taking account of competing demands on their time from other formal work commitments.

More broadly, the CC had to demonstrate considerable flexibility in managing the census collection process, including managing the work of the interviewers. Competing demands on the interviewers' time came not only from other work commitments, but also from within the Aboriginal domain, in terms of their involvement in the flux of everyday social and political process including commitments arising through formal and informal 
responsibilities to kin. Furthermore, the quite intensive and demanding nature of the actual census collection work was not necessarily in keeping with Wik attitudes and practices regarding 'work'. While obtaining an accurate census count and its ancillary information may objectively have been of importance, and this had been explained to the interviewers, it is typically the exigencies of mundane life which provide the imperatives for Wik people (Martin 1993). This of course was not just the case for the interviewers, but indeed for other Wik residents in terms of their participation in the census.

This inevitably meant that the only effective census methodology was to work within the parameters set by the ebb and flow of life within the township, and the CC was clearly very aware of this factor. One important consequence of this was that it would not have been possible to complete the census over the nominal census night of Tuesday 7 August, and like census collections in other remote Indigenous communities the collection necessarily had to be conducted over a more or less extended period. This of course has implications for the accuracy of the broader census - for example, given a highly mobile population in some regions, conducting the census over an extended period across a region may have the potential to lead to both double counting of some individuals and the missing of others.

However, it also has implications for the type of information collected directly by census interviewers in remote communities, since much (but not all) of the additional time required relates to the level of detail collected on each SIPF that is elicited from respondents, rather than (for example) from local administrative data sets. This in turn relates to what the central focus of the census should be for such remote populations; the basic demographic profile, or the wider questions covered in the personal forms. This issue is raised in the other case studies in this volume.

Effective and appropriate management of the overall census process in Aurukun therefore involved management of such factors as the periodic unavailability of interviewers, provision of proactive support and assistance to interviewers, and being able to direct the actual collections to take advantage of opportunistic lulls in the ebb and flow of community life and its priorities, for both interviewers and general residents. It therefore required a quite difficult balance between flexibility (in dealing with the high levels of mobility and the various exigencies arising during the collection process), and systematicity (in ensuring that the collection encompassed as far as possible all Aurukun residents, and that the accompanying paperwork, particularly the forms, was systematically processed and stored).

\section{Compiling the Dwelling Check List}

Eventually, by late morning on Monday 6 August, the main Aboriginal interviewer was able to leave his other work and come down to the census centre. Together with the CC, he worked systematically through the Shire Council map of the township, assigning family names to each of the dwellings in each sector for the purposes of developing a preliminary the Dwelling Check List. The 'family name' which he assigned was essentially that of the person whom he considered the most significant in the household, equivalent to 'person $1^{\prime}$ of the SIHF. 
However, in many cases a particular dwelling would be considered to be that of an individual who was actually living elsewhere in the township (and sometimes away from Aurukun altogether). Also, the 'family name' assigned to a particular household on the Dwelling Check List would often not be that of many or even most of the residents, who could for instance be in-laws, nephews, nieces, visitors, and so on.

A further difficulty was occasioned by the fact that the initial map provided by the Aurukun Shire Council was out of date. With the help of the principal Aboriginal interviewer, a quite significant number of vacant or unoccupied dwellings were identified and marked on the map. These ranged from derelict houses awaiting either refurbishment or demolition, to houses temporarily vacant under ritual restrictions following deaths. As well, houses constructed since the time that the map had been drawn up were marked and numbered. Even so, once interviewers started the actual work of filling in forms in each sector, a number of changes had to be made to the Dwelling Check List for certain sectors.

\section{Filling in the Household and Personal Forms}

Interviewer teams that I observed usually - but not always - started the gathering of information on the SIHF and SIPFs with statements about what the census broadly entailed, and of its significance in terms of getting an accurate count of the population so that Aurukun could receive the necessary levels of funding for housing and other infrastructure.

The teams had to be very flexible, and adapt their interviews to the flux of social life in the township. This meant working around the 'wages or welfare payments, alcohol consumption, conflict and dislocation' cycle to which Aurukun was subjected, like many other remote communities with liquor outlets. It also meant that if there was a group playing cards at a dwelling (a major social and economic activity within Aurukun), the interviewers would leave it till a later time, as it would have caused embarrassment and possibly hostility to interrupt the game.

The procedure usually started with the interviewer attempting to elicit the names and relevant details of residents for the SIHF, before then moving to the SIPFs. In some cases, the Aboriginal interviewer sat beside the respondent, filling in most of the information himself without directly questioning the respondent who watched closely as he wrote it down. In others, people were reluctant to come out of their dwellings and assist in filling out a SIPF. I was advised that one Aboriginal male-only interviewer team had difficulties in eliciting responses from younger women. However, in the cases I observed, I was not aware that this might have arisen because of kinship-based or other restrictions between the person and the interviewer. Rather, it seemed to derive from a strong resistance to being involved in an activity in which the person was totally disinterested. In such instances, the interviewer respected the right of that individual to refuse to participate, in accordance with the importance accorded by Wik to the principle of personal autonomy, and filled in as much of the form as he could himself, with assistance or corroboration from relations on certain questions. 
The principal Aboriginal interviewer frequently used humour as a device to circumvent the intrinsically alien nature of the census process. For example, in filling in the form for a young woman classified as his daughter-in-law, and therefore notionally subject to avoidance restrictions, he joked his way through the questions, for example: 'You man or women, eh?', and 'You Island woman eh?'. The use of humour was particularly helpful in eliciting information from children, bringing them and their sharp capacity for observation into the census enterprise. For Wik people at least, this could be construed as 'culturally appropriate' behaviour, since by inverting the usual behavioural codes, the Aboriginal interviewer was also framing the enterprise of collecting the census information as an inversion of normal appropriate behaviour. Implicitly, then, he was also creating a sardonic commentary on the 'silliness' of the census and its questions which was only fully appreciated by Wik people themselves. This particular mechanism would certainly not necessarily be appropriate for other groups, and required an insider's sophisticated knowledge of the bounds of acceptable practice.

Some individuals were provisionally listed as residents of a particular dwelling, but a note was made to check and validate their place of residence at the end of the census collection since they moved between a number of households. This was particularly the case for many children and young men.

\section{Responses to census questions}

This section gives brief accounts of some of the issues I observed in relation to specific census questions (see Appendix C for the full forms of the questions on the SIPF).

\section{Question 3}

Many people, especially children and teenagers, were not aware of even their approximate ages. Not infrequently, respondents were unsure of the ages of their adult children, of coresident in-laws, or of actual or classificatory grandchildren living in the household.

\section{Questions 4 and 5}

These questions were enormously problematic for Wik people, both in terms of the opaqueness of what it was that was being sought, and in terms of their potential to seriously misrepresent a fundamental set of principles in Wik society (see also extended discussion in Morphy, this volume). One non-Wik interviewer stated that Q. 4 and Q. 5 were 'stupid' and 'offensive'.

The meaning of Q. 5 in particular caused considerable difficulty, including to the interviewers. Some respondents, for example, stated that their closest relation in the house was their child. Others however, ignored closer genealogical relations to nominate a person who had a closer classificatory or other relationship (see immediately below). For Wik people, 'closest' relation refers not just to genealogical distance, but also to the complex combination of that factor and social and political distance. 
Often after prompting from the interviewer, people gave their relation to 'person 1 ' in terms of the simple English equivalent of the Wik kinship term. However, the core conceptual problem is that the kinship system for Wik people provides a fundamental organising principle for their society. Wik kinship terminology is 'classificatory', in the sense that it does not simply refer to close consanguineal kin, but has specific principles by which terms can be extended to classes of people in certain actual or putative relationships. Thus, for example, one's grandfathers and grandmothers are not just the parents of one's actual father and mother, but also include all those persons who are classified in the same generation as one's parents' parents. As another instance, those whom one terms 'father' include not only one's genitor, and possibly also one's mother's husband, but additionally all those whom these individuals classify as 'brothers'.

'Person 1' therefore could have in his or her household more than one mother, a number of cousins, several grandfathers, and a number of sons and daughters who might or might not be their or their spouse's actual children. All these terms would be the English equivalents of particular Wik classificatory kinship terms. Additionally, it could not be assumed that even closely related individuals within the same household shared the same family name; for example, a child could be living with his mother but have taken his father's surname. Conversely, individuals sharing the same surname and living in the same household at the time of the census would not necessarily be from the same nuclear family, although in all likelihood they would be 'family' in the Wik sense.

More broadly, co-residence (even in the limited sense of who sleeps where), commensality, family groupings, and domestic economic units are not necessarily coterminous - for instance, people who live together may not eat together. In common with the situation reported for other Aboriginal groups (Altman 1987; Anderson 1982; Finlayson 1991; Smith 1991, 1992), basic economic and social units of Wik society are comprised of linked households rather than individual ones (Martin 1993). Furthermore, what Aboriginal people themselves refer to as 'families' are typically dispersed across a number of households, as shown in Fig. 2.1 overleaf. This describes a cluster comprising five households drawn from a single 'family' group based on a focal individual and his descendants.

It is clear from the above, and from the observations by Morphy (this volume), that the versions of household relationships recorded on personal forms and which inevitably used English equivalents of Wik kin-based reckoning of relationships could at best offer an impoverished version of the complex maps of social relations with which such traditionally-oriented Aboriginal people operate.

Of course, the census is not designed to reproduce ethnographic realities. However, one can presume that the inclusion of this question in the general census is an attempt to get a broad handle on the changing composition and structures of Australian households over time. The mismatch between the actual complexity of remote Indigenous households such as those in Aurukun, and the impoverished versions that would be recorded on census forms is such as to render the data essentially worthless for this purpose. At most, one could deduce that almost all households involved complex extended family structures. 


\section{Fig. 2.1 Example of a 'cluster' of households, Aurukun}

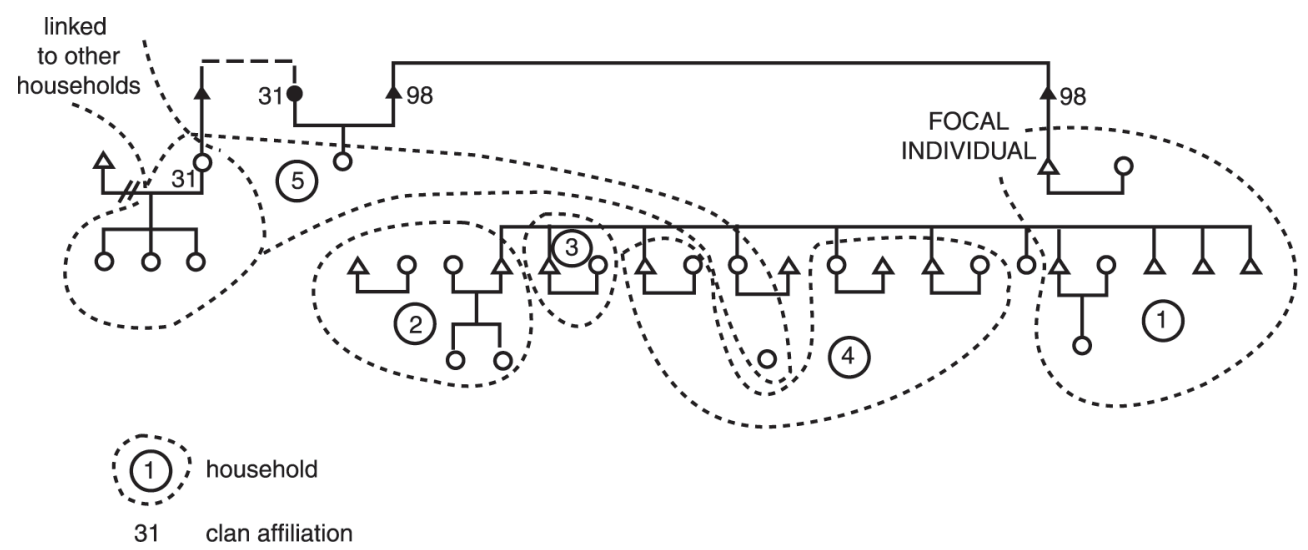

Source: Martin 1993.

Furthermore, serious concerns must also be asked regarding the validity of the ABS using such data to ascertain family types within households, and the comparability of these findings with those from other sectors of the Australian community. Preliminary results from the 2001 Census provide a breakdown of 'family types' for Aurukun. Table 2.1 provides a summary of the published data, excluding for my purposes here those families where the reference person and/or spouse or partner did not state their Indigenous status. Family types are broken down into couple families with and without children, one-parent families, and other families.

Table 2.1 Family types, Aurukun, 2001 Census

\begin{tabular}{lcc}
\hline Family type & Families (no.) & Persons (no.) \\
\hline Couple family & 72 & 389 \\
Couple family with no children & 32 & 80 \\
One parent family & 84 & 351 \\
Other family & 6 & 24
\end{tabular}

The preceding argument suggests that it is quite invalid to attempt to derive such putative 'family structures' within a particular household, modelled as they are on those of the general Australian society, from the information recorded on the SIHFs and SIPFs. This information comprises for this purpose only the occupants' family names, the English terms for their relationships with 'person 1', and potentially the name of another person in the household to whom they are more closely related, and their relationship to that person. Attempting to cross-validate the nature of the relationship recorded by reference to family 
names would add no additional rigour, for the reasons outlined above. Such doubts are exacerbated by, but not confined to, issues surrounding the difficulties people had in answering Q. 5 on the SIPF.

\section{Question 6}

Responses to this question were treated idiosyncratically by individual respondents. Some with long-term de facto partners stated that they were 'married', while others in the same situation stated that they were 'never married'. At least one person in a long-term relationship refused on principle to have 'married' entered as his status, insisting that if it could not be entered as 'de facto' it had to be entered as 'not married'.

\section{Questions 7, 8, and 9}

A series of well-known but nonetheless important issues underlie the difficulties people faced in responding to these questions. Firstly, there is the fact of high mobility rates. People may not be sure where they lived one year ago, or even more five years ago. Phrasing in terms of last 'dry season' as suggested on the SIPF did not necessarily assist. Asking if the dwelling where they are being enumerated is where they live 'most of the time' may not be particularly meaningful for (say a young man) who moves on a frequent basis between households, or even between communities. For many people, it is mobility which is the norm, rather than stability in terms of place of residence-I was asked by a middleaged man who had visited me in Canberra two months previously if I still lived in the same house!

Related to the above, there is both a high attrition rate and a high construction rate of houses in Aurukun. For many respondents, it was difficult to specify where they lived (say) a year ago, because the house they thought they might have been in no longer existed. While some of the new houses had been erected on sites occupied by now-demolished houses, others were on entirely new sites. While the township streets were named, there was not a conventional lot numbering system. The numbers used on the form were those allotted to houses by the Shire Council, which were not on a street but on a township-wide basis. This made the coding of places of residence one and five years ago even more problematic.

These practical difficulties underlie another issue; it was not clear to the CC or interviewers whether the SIPF aimed to determine only mobility between communities or SLAs, or also that within communities and SLAs. The latter is well demonstrated in ethnographic studies (see discussion above) but whether this is a useful output from a national census may be another question.

I should note here that some difficulties were occasioned by Q. 6 on the SIHF (see Appendix B), regarding from whom the particular house was being rented. All housing stock in Aurukun (apart from government housing for teachers and so forth) is owned by the Aurukun Shire Council. People seemed to idiosyncratically fill in one of the 'community housing group' or 'Government housing authority'. 


\section{Questions 10-13}

These questions caused problems for interviewers and respondents alike. For a start, my observations of the relatively few Aboriginal people of mixed ancestry in Aurukun were that (for some) Q. 11 and (particularly) Q. 13 caused both embarrassment and bafflement. This is despite the fact that, unlike certain regions in the Northern Territory, to be of mixed descent is not the subject of adverse comment by other Wik Aboriginal people. Rather, the question directly raised (in a semi-public context) the issue of the individual's paternity. Wik interviewer, respondent, and Wik audience, would all have known in each case the imputed paternity of the individual, since such matters are the stuff of everyday gossip and speculation. However, respondents of full descent were not confronted with the same dilemma, whether or not there might be speculation about their actual paternity, since Q. 11 and Q. 13 allowed them to still preserve a general anonymity.

Questions 11 and 12, regarding where the respondent's parents were born, also occasioned diffidence in responses from some, not because they were of particular moment, but because on the contrary the answer was so self-evident. This was but one illustration of an inevitable issue; the necessary question and answer methodology of the census form can result in diffidence, embarrassment, or even hostility for people who, within their own cultural milieu, use quite different means of eliciting information, or of validating information that is already known to be shared. The interviewers often avoided this problem by either prompting the answer for such questions, or simply filling them out without comment.

\section{Question 15}

This question clearly caused embarrassment to many if not most respondents. Mostly, interviewers did not even ask this question, or if they did, it was in a clearly rhetorical manner ('You speak English well, eh?'). All interviewers I observed entered either 'well' or 'very well' to this question, even in cases where, to the best of my knowledge, the individuals concerned, young teenagers for example, had quite a limited grasp of English. These observations were borne out in the preliminary census results released for Aurukun and its outstations by the ABS, and shown in Table 2.2 below. These data suggest that the overwhelming majority, some 75 per cent, speak English well or very well, which is not borne out by ethnographic observation.

Table 2.2 Language spoken at home and English proficiency, Aurukun, 2001 Census

\begin{tabular}{lrr}
\hline Language spoken & English spoken & Persons (no.) \\
\hline English only & & 52 \\
Aboriginal language and English: & well or very well & 696 \\
& not well & 106 \\
& not at all & 41 \\
& not stated & 4 \\
\hline
\end{tabular}


To make sense of these results, it is important to understand that these responses were not technical in nature but symbolic. As described below, Aurukun had been a church mission until 1978, and the missionaries had placed considerable emphasis on teaching English. As the result of their internalisation of the missionising enterprise within a particular Aboriginal framework, for Wik people of older generations in particular, to be able to speak English well is a sign of being 'civilised', of not being a 'myall'. In arguments, people will disparage others' English capabilities, and conversely boast of their own relations' fluency (Martin 1993). To answer this question with a statement of objective limited capacity, therefore, in a more or less public place (since interviews were almost always conducted outside dwellings with numbers of people present), would have had a powerful negative symbolic import.

\section{Question 16}

Aurukun had been a Presbyterian, and later a Uniting Church, mission until 1978. Some (usually) older respondents stated that they were Uniting Church. Many others, especially younger people, stated either that they had no religion, or that they did not wish to answer the question. In fact, the religion question seemed to be largely meaningless to younger respondents. Some interviewers did not provide this option when discussing this question. Not one person that I observed answered 'Traditional Beliefs' to this question, even when interviewers (following discussions with myself) specifically asked this and provided some explanation of what this term might mean. These observations were borne out in the preliminary census results released for Aurukun and its outstations by the ABS. A summary is shown in Table 2.3 below. This data suggests that only a little over 1 per cent of Aurukun's Indigenous population adhere to traditional religious beliefs.

\section{Table 2.3 Religious affiliation, Aurukun, 2001 Census}

\begin{tabular}{lc}
\hline Affiliation & No. \\
\hline Uniting Church & 171 \\
Other Christian & 12 \\
No religion & 9 \\
Traditional Aboriginal religion & 11 \\
Not stated & 715 \\
\hline
\end{tabular}

Yet, Aurukun can still be considered one of the most traditionally oriented communities in Queensland. The Wik people, including those in Aurukun, had only recently had native title over much of their traditional lands recognised, in a process which required extensive documentation of traditional beliefs and practices to be presented to the State government for the purposes of a consent determination. There is a strong system of belief in 'supernatural' forces underlying much of mundane life, including a strong attribution of causality (including through sorcery) which is quite distinct from that of even religious non-Aboriginal Australians (see e.g. McKnight 1981; Martin 1993; Sutton 1978). Why would people therefore resist acknowledging their traditional beliefs? 
It could be that one factor is a reluctance to have what lies in the private or internal Aboriginal domain exposed to non-Wik people - but against that argument, Wik people are notoriously outspoken in their views about their cultural distinctiveness. Alternatively, it could be that equating 'Traditional Beliefs' with, for example, 'Uniting Church' in a question about 'religion' is confusing to people. To test this hypothesis, I actually asked this question of respondents myself on two occasions, including using Wik Mungkan, but with no different result.

It could be argued that Aboriginal respondents could see this question in some ways as seeking complementary information to Q. 15 (how well do you speak English). As discussed above, the latter was clearly interpreted by Aboriginal interviewers and respondents alike as being equivalent to asking whether the person was a 'myall' or uncivilised, and it is conceivable that answering Q. 16 in terms of holding 'Traditional Beliefs' would be similarly interpreted, in the context of a census form whose ultimate purpose and destination were quite opaque to almost all Aboriginal people in Aurukun.

In any event, whatever its origin, if this response is broadly consistent with that from other remote Aboriginal groups, one would have to question both the utility of this question (at least as phrased), and also any inferences that might be drawn by subsequent research on the census data concerning the incidence of traditional beliefs amongst remote Aboriginal people.

\section{Questions 19-26}

My observations were that if the way in which answers to these questions were given was typical, the census is unlikely to provide a reliable source of data on education and training levels of Aboriginal people in remote communities.

For example, attendance at the Aurukun school has been very low for many years now. Yet, most people that I observed stated in response to Q. 19 that their children went to school, although some rationalised the fact that children were around while the census collection was taking place (during school hours) in terms of such factors as teasing or fighting in the school.

Even for questions concerning post-school courses undertaken, it proved very difficult to elicit clear responses from this cut-and-dried question and answer format. There have been an absolute plethora of training courses which Aurukun people have been involved in over the past few years, and respondents were often vague about the technical details of these courses.

\section{Questions 28-38}

Many respondents were not sure of what their before-tax income was. In fact, there is a good argument that Q. 28 (on income) should have followed Q. 29-35. This is would have allowed a logical progression from the general to the particular in the information being sought. Most people are on CDEP, and working from that fact to the number of hours worked would then have allowed the informed interviewer and respondent to jointly estimate the fortnightly income more accurately. 
As with dwelling locations, difficulties were encountered in precisely identifying the addresses of people's workplaces; for some CDEP participants, it was entered as 'the yard'. Where interviewers were aware of who worked on CDEP and how many days they worked, the 'hours worked' question was relatively straightforward, since participants worked either two or four seven-hour days. For those on Jobsearch, living in an area where there was virtually no work available, there appeared to be some confusion as how to answer Q. 37 and Q. 38, regarding looking for and availability for work.

\section{Question 39}

Census interviewers had a lot of trouble in developing meaningful explanations of this question, and respondents had considerable difficulty in providing meaningful responses to it. In some instances, no attempt was made by the Aboriginal interviewer to provide an explanation, and after an uncomfortable silence, the respondent stated that the information could be kept. Attempts to explain the option in terms of providing a resource for future generations to research family links and so forth made no sense to people at all. For one thing, Wik people hold a deep knowledge of kin links and of the flux of political and social relations - reflected in household compositions at any given time - which is quite independent of any administrative recording of such relations. For another, this question is at the end of the SIPF and follows the manifestly problematic attempts to ascertain information on familial links in Q. 4-6.

\section{Question 40}

The format of this item in the SIPF assumes that the interviewer directly interviewed the person named in the form. This was not so in many cases. The interviewer presumably then could have left both Q. 39 and Q. 40 blank. However, interviewers in some of these instances seemed to assume that their signing off the Declaration was not just in relation to $\mathrm{Q} .39$, but in relation to the information in the form as a whole.

\section{Completion of the count}

In the event, the Aurukun census count took almost a month to complete. This was for a range of reasons which were already apparent early in its conduct, including the difficulties in ensuring that as many Indigenous residents as possible were located and recorded, and problems with the availability and commitment to the project of some interviewers.

Conducting the census over such a long period of course has the potential in mobile populations to lead to significant overcounting. Active steps were taken by the Census CC to minimise this. For example, as discussed above, a number of people had travelled to Pormpuraaw for a football match there, and were away for the first week of the census count. The CC checked with a number of these individuals on their return to Aurukun to ensure that they had not been included as visitors in the Pormpuraaw census. Checks were made of a number of individuals who had travelled to Cairns for medical or other reasons to ensure that they had not been included in the census there. 
Aurukun's population is characterised by a very high internal mobility (Martin 1993; Martin \& Taylor 1996). To minimise the possibility of overcounting because of the extended time taken to conduct the census, the CC prepared a computerised list of all persons recorded on the census forms. Some 40 to 50 individuals, mostly younger children and teenaged boys, were found to have been recorded in more than one household, and duplicates were removed.

As had been planned, spot interviews were undertaken at places such as the store, airport and tavern and outside houses, to ensure that as many people as possible had been recorded in the census. The CC also checked each SIHF and SIPF for completeness of data. The one exception was a mixed household of Indigenous and non-Indigenous residents who insisted on the confidentiality of their forms.

As a final comment on the extreme thoroughness with which the Aurukun census was conducted, the CC was concerned about problems in handling bulky parcels through the mail system from Aurukun to Cairns, and the absence of sufficiently robust packaging, and thus personally delivered the forms to the ABS office in Brisbane.

\section{Conclusion}

The conduct of the 2001 census in Aurukun could, from some perspectives, be seen to have been exemplary in terms of its combination of flexibility in a highly challenging environment, systematicity in its collection methodology, and rigour in cross-checking and validating the data collected. Consequently, it is no surprise that the preliminary 2001 census count for Aurukun, at a total Indigenous population of 921, is significantly higher than that from previous census counts; the number of Indigenous residents recorded in the 1996 census was 792. The result would appear to be more commensurate with earlier detailed ethnographic counts (Martin \& Taylor 1996).

At the same time, it is clear that the time and human resources committed to the Aurukun census, if repeated elsewhere, would have major implications for the ABS. Were such extended counts to be widespread for the highly mobile Indigenous populations common in remote areas at least, there would be a significant risk of double counting some people, while still missing others. On the other hand, it could be argued that such overcounting would only compensate for the range of other factors which lead to undercounting (Martin \& Taylor 1996).

Finally, ethnographic observation of the Aurukun census count, like that in the other case studies in this volume, raises important questions about the rigour and comparability of much of the data recorded on the census forms. It also raises questions about the validity of using census data to derive remote Indigenous population characteristics by means of methodological assumptions appropriate for the general Australian population but not for remote Indigenous people. The ABS have made laudable advances in their Indigenous remote area census methodology, but there is arguably still progress to be made in maximising the capacity of census questions to provide data relevant to central policy issues in Indigenous affairs. 